\title{
New Discovery of a Psychoactive/Medicinal Plant (The Oba Plant)
}

\author{
Joel Tobechukwu Kingsley
}

\section{Department of Agriculture, Ethiopian Institute of Agricultural Research, Awka, Anambra, Nigeria}

\section{PERSPECTIVE}

Oba Plant is a powerful working medicinal/psychoactive plant that was show in a dream to a man by name George Okafor, who happens to be curing sicknesses and illnesses with herbs or herbal medicines. The plant grows very scarcely in some swampy areas in the eastern part of Nigeria and could be classify on the family of nightshade or aubergine plant.

Through series of researches and experiments, Oba plant was observed of having so many medicinal benefits and significances, and without any doubt, I have this full assurance that the plant must have or contain great qualities of either known or unknown compounds that could be very effective against microbial diseases and so on, and more importantly the stimulant and hypnotic effects of it.

Oba seeds and leaves are the major parts of the plant where the medicinal effects were observed to be contained, but more importantly, the seeds that was observed and identified of having so many benefits like medicinal, stimulant and hypnotic effects, though, other parts of the plant might have its own medicinal benefits and significances but no research have been carried out on it for a proof.

Oba plant seeds as observed, could mysteriously raise the level of psychological or neurological activities of people for hours after taking it with either soft or strong drinks, whereas, made some people to sleep off in minutes after taking it, and could cause such people to sleep for about 12 hours depending on the amount of the drug application and the level of their body system or energy.

Another observation or result from an experiment carried out with the Oba seeds was when the concoction was administered with a terribly sick goat, and surprisingly, few hours after being administered with the concoctions, the goat was totally healed and revived.

Oba seeds could also contain some nutritional values or contents because of its natural taste of sugar and a good smell of beverage like.

And also, the leaves of the plant could surprisingly heal one from a chronic toothache that has lasted for years.
Through research and experiment, burning few leaves of the plant in a plate with some pieced charcoals could cure a toothache patient mysteriously by inhaling the smoke that was coming out from the burning leaves through the mouth, and immediately as the smoke entered the holes in the teeth, the germs causing the toothache could be force out from the holes and that was in turn put an end to the toothache that has lasted for years.

Oba leave is also use for treating whitlow virus by applying the grinded form of the leaves on the affected finger, and by so doing, the pains and swollen part of the finger will get reducing, and before you know it, the ailment will be a thing of the past.

I believe, there could be other great medicinal and nutritional significances of Oba leaves and seeds if properly analyzed biotechnologically, that is the reason I am mostly concerned about how to further the proper research on it in order to know the kind of compounds that will emerge from it which contributed to the amazing healing properties, raising of psychological or neurological actives.

Oba seeds and leaves worth exploring and finding out the compounds present in it which I strongly believe could be very useful in the pharmaceutical companies and other wise.

\section{SUMMARY}

Nowadays, the use of herbs for treatment and healing of diseases have been slowly disappearing even in some villages in African continent, and this is because people have come to relying and embracing the chemical drugs for proper prescription in regard to their health. Many chemicals were some of the compounds isolated from an ethyl acetate soluble fraction of methanol extracts of some plants and through invitro assays were found to have great potential anti-disease effects, similarly, Oba seed and leave could also contain many other unknown compounds with great therapeutic properties considering the experiments carried out. Oba plant seeds as observed could contain great an aesthetic effect which I strongly believe will be useful to induce insensitivity of pain before surgical operation.

Correspondence to: Tobechukwu Kingsley, Department of Agriculture, Ethiopian Institute of Agricultural Research, Awka, Anambra, Nigeria, Tel: + 2348025734937; E-mail: tobe.kingsy@yahoo.com

Received: February 11, 2019; Accepted: March 15, 2019; Published: March 27, 2019

Citation: Kingsley JT (2019) New Discovery of a Psychoactive/Medicinal Plant (The Oba Plant). Nat Prod Chem Res. 7: 358. DOI: 10.35248/2329-6836.19.7.358

Copyright: (C) 2019 Kingsley JT. This is an open-access article distributed under the terms of the Creative Commons Attribution License, which permits unrestricted use, distribution, and reproduction in any medium, provided the original author and source are credited. 